\title{
A reflection on medical anthropology and epidemiology
}

\author{
Craig R. Janes
}

\section{Keywords}

anthropology and epidemiology, HIV, clinical trials

The essays in this issue's Interventions section, by Denielle Elliott and Timothy Thomas, Kristin Peterson and Morenike Folayan, and Eva Vernooij, describe anthropological engagements with the global public health enterprise that we could not have imagined in the late 1970s and early 1980s, when my coeditors and I were developing the ideas that led to the publication of Anthropology and Exidemiology (Janes, Stall, and Gifford 1986). Medical anthropology was a young field and we were amongst the first few cohorts of students to receive PhDs in it. Many of us had been motivated to consider anthropological contributions to public health through the mentorship of Fred Dunn, a physician-anthropologistepidemiologist who was deeply committed to the utility of medical anthropology in communicable disease epidemiology (Inhorn and Janes 2007). The exploration of the social contexts of sickness was not, of course, a novel line of thinking: in many ways we were simply building on genealogies of knowledge that harkened back to the work of Rudolf Virchow, Friedrich Engels, Emile Durkheim, and others (Trostle 1986b, 1986a). Exemplary thinking had already been done by Sidney Kark and his colleagues and students in South Africa, which in many ways laid the foundation for the development of an anthropologically informed social epidemiology (see Kark and Abramson 2003); Alexander and Dorothea Leighton and their colleagues in their often-neglected work on the social and cultural factors 
in community mental health in Stirling County, Nova Scotia, and elsewhere (Leighton 1959; Leighton, Lambo, and Hughes 1963; Leighton et al. 1963); and Ben Paul's (1955) classic early work. But there were several other conceptual developments at the time that for us promised a new kind of intellectual partnership between anthropology and epidemiology.

The first derived from the aforementioned work of Fred Dunn. As Marcia Inhorn and I (2007) have written, Dunn's work was unique for many reasons. He moved beyond the narrow risk-factor thinking that had informed much of social epidemiology up to that point. Perhaps because of his training in and orientation to the ecology of communicable diseases, he articulated a far more careful approach to identifying behavioral causes that included what now are recognized as factors of structure and agency. His focus on communicable disease ecology also brought to the fore principles of systems thinking, especially the importance of socioecological dynamics in understanding the relationship between humans, vectors, and microbes. This focus on ecology highlighted a unique contribution of anthropology to the study of communicable diseases, one that we see manifest today in research on emerging vector-borne diseases and in several novel interdisciplinary initiatives where anthropology is well represented, for example, the Ecology and Evolution of Infectious Diseases program supported by the US National Science Foundation (NSF) (Janes et al. 2012; NSF 2017; Trostle et al. 2008; Singer 2014; Inhorn and Brown 1990). ${ }^{1}$

Secondly, in the 1970s and 1980s medical anthropology was making a shift from the study of non-Western medical systems to a more focused and critical analysis of biomedicine, explorations of a biocultural synthesis, and adoption of critical social theory. The field was opening up, offering possibilities for new avenues of scholarship that intersected with a number of disciplinary traditions and promised to facilitate new kinds of questions (Inhorn and Wentzell 2012). Rather than being consigned to narrating and applying local knowledge, this new direction stimulated anthropologists' engagement in novel forms of interdisciplinary work, including ethnographically informed analyses of the plausibility of causal relationships.

The Ecology and Evolution of Infectious Diseases program supports research 'on the ecological, evolutionary, and socio-ecological principles and processes that influence the transmission dynamics of infectious diseases'. Funding is provided by the NSF, the US National Institutes of Health, and the Biological Sciences Research Council in the UK. At the NSF, funding is provided by both the Directorate for Biological Sciences and Geosciences, as well as for Social, Behavioral, and Economic Sciences (NSF 2017). The Cultural Anthropology program at NSF has played an important role in the adjudication of EEID grant proposals. 
In the early 1980s the HIV epidemic, which was provoking a great deal of concern, was also seen as a particularly important area for focused anthropological scholarship.

Thirdly, epidemiology itself was undergoing significant conceptual and theoretical developments that led it to explore with greater intensity the biological consequences of social relations and culture change. Exemplary is the work of Len Syme and his students and colleagues at Berkeley who laid the foundation for a theoretically informed social epidemiology (Syme 2005; Krieger 2011; Marmot and Syme 1976; Berkman and Syme 1979). Consider the exemplary work of Michael Marmot, who went on to lead the Whitehall Study of British Civil Servants as well as the World Health Organization's Commission on the Social Determinants of Health, and the work of Lisa Berkman who with Syme led the Alameda County study and went on to do critical work on the role of social networks and social support in health and aging. Nancy Krieger's work is especially noteworthy. A tireless advocate for social justice, Krieger is one of the world's most highly cited researchers and credited with the development of ecosocial and embodiment theory in epidemiology (Krieger 2001, 2005). At Berkeley, several of my peers in the medical anthropology program worked with Syme and other like-minded epidemiologists; some completed master's degrees in public health there. I was greatly influenced by these scholars in my own early work documenting the social and cultural processes leading to elevated cardiovascular risk in immigrant communities (Janes 1990). So while medical anthropologists often tend to focus on anthropological contributions to epidemiology, it should be clear that medical anthropology owes a great deal to these remarkable scholars. Several lines of contemporary inquiry, for example, are complementary to or expand on this scholarship: William Dressler and his colleagues' research on cultural consonance and health outcomes (for example, Dressler 2001); Clarence Gravlee's work on the mechanisms through which race and racism affects patterns of disease (for example, Gravlee 2009); and the burgeoning scholarship on syndemics that has just achieved significant recognition in a new Lancet series (for example, Tsai et al. 2017; Singer et al. 2017).

Perhaps because many of us who edited and contributed to the book studied epidemiology with social scientists who were optimistic about the contributions of anthropology, we were less likely to stumble over methodological and epistemological differences, though we certainly recognized these. My first encounter with epidemiology was in a first-year course taught primarily to medical students at the University of California, San Francisco. The course was taught by Virginia Ernster, an extraordinary instructor who had come to epidemiology from the discipline of history and who also held an appointment in UCSF's medical anthropology program. In an early session, we were presented with what is now a classic example in social epidemiology: the death records of those who perished in the Titanic's sinking, with variation in mortality evident by age, gender, and economic status. 
Prior to divulging the source of the data, Ernster asked us to consider the nature of the 'unusual episode' that caused such variability. The example, of course, reveals the impact of social and economic inequity on mortality, lack of essential resources (lifeboats and life vests), effects of the environment (how far below deck that berths were located and access points to the deck), as well as the significance of 'culture', in this case the Victorian ideal of 'women and children first' (Trostle 2005). In working through this example and several others like it, I learned that doing epidemiology was about looking for the nonobvious, viewing all evidence with a critical eye, puzzling out hidden relationships, discerning biases, and identifying potential confounding factors or effect modifiers. ${ }^{2}$ In this way I found it to be quite a bit like anthropology in its intellectual motivations. Both disciplines celebrate critical thinking. Epidemiologists are unwaveringly critical in their evaluation of evidence. Anthropologists are critical in their analysis of social relations of power. It seemed obvious to me that bringing the disciplines together in complementary relationship would open vast possibilities for making anthropology relevant to public health and vice versa.

Despite these areas of complementarity, the relationship between medical anthropology and epidemiology has not been an easy one. This is due to several developments, both within the disciplines and within global public health more generally. When we were exploring the relationship between the disciplines in the 1970s and '80s, medical anthropology seemed less troubled by the epistemological divide between the inherent positivism of epidemiology and the postpositivist, interpretivist turn that would come to increasingly characterize cultural anthropology. Cultural anthropology had not yet assumed its fully dominant position within medical anthropology. This tension was and continues to be particularly challenging for medical anthropologists working in applied, public health contexts, and may explain the barriers that medical anthropology as a subdiscipline has experienced in taking on and grappling with new and emerging topics that require greater rapprochement with public health, for example climate change, ecological determinants of health ('ecohealth'), and 'planetary health'.

It is important to note here that, as in many disciplines, epidemiology has two modes of inquiry: analytical and descriptive. Analytical epidemiology, which is what I principally refer to here, is concerned with the analysis and establishment of causal relationships. Descriptive epidemiology is, as the term implies, concerned more with the collection and presentation of indicators and metrics of sickness in populations. There has been considerable criticism of the (mis)use of such indicators in global health (see, for example, Adams 2016). Analytical epidemiology, certainly that which focuses on social and behavioural factors in disease causation, tends to be theory-driven (see for example Krieger's work 2001, 2011). See also Dunn and Janes 1986. 
When we were writing and editing Anthropology \& Epidemiology we were aware of the looming HIV problem, and included an important, early paper on the San Francisco epidemic (Gorman 1986). At the time, we could not have imagined how it would come to both dominate as well as offer multiple opportunities for anthropological engagement with global public health. David Wilson (2017), current director of the World Bank's HIV/AIDS programs, credits the international response to the HIV epidemic for three critical changes to global health: responses to the epidemic quickly transcended the dominant biomedical model in communicable disease research, the global HIV/AIDS advocacy movement laid the foundation for a rights-based discourse in global health, and the movement helped build a tremendous, bipartisan American coalition that led to the largest public health intervention effort in history. In the early days of the epidemic it was clear that social and behaviorally oriented prevention was the only avenue available to manage the disease, and this opened up multiple avenues for engagement with the social sciences. Anthropologists, with their knowledge of local contexts and communities where the epidemic was fiercest, were swept up into these programs. In these contexts, as the essays in this issue elaborate, the challenges of working within a larger public health/epidemiologic enterprise became increasingly fraught.

Perhaps what troubles the medical anthropology/public health engagement in the context of the HIV response is what Wilson (2017) calls its 'remorseless implementation'. Global HIV prevention and treatment programs became a medical-industrial complex, focused with a 'laser-like' intensity on the disease. Massive funding from both public and private sectors, coupled with the creation of a single-issue management architecture - including the Global Fund, the President's Emergency Plan for AIDS Relief (PEPFAR), the United Nations Joint Programme on HIV/AIDS (UNAIDS) - created a scientific governance apparatus that was not particularly well-suited to careful considerations of local contexts, and often inattentive to the need for effective and responsive national health systems (see Uretsky 2017). Multicountry clinical trials have become the hallmark of the HIV industry. Organized and led by scientists from the global North, and dependent on the consistent application of trial protocols across settings, these trials afford neither the easy opportunity for tailored, local implementation nor effective and ethical partnerships with local scholars. The role for medical anthropologists in these settings is a difficult one: at once collaborators, critics, analysts, and proponents of local interests. The essays here well illustrate these challenges. A point made by Elliott and Thomas (this issue, 12 ) is especially apt: 
Ethnographers are fundamentally trained to think about the historical, political, economic, social, and cultural contexts of things, peoples, events, and spaces. HIV is never just a virus to an anthropologist. It is raced, sexed, gendered; it is shaped by capital accumulation, colonialism, migration, displacement, and violent encounters. Treatments, preventions, and possible cures are similarly shaped by these forces and histories, and so a clinical trial is never only medicine in the making, void of context.

When I was a graduate student we worried about becoming the 'handmaidens' of biomedicine, used to facilitate its inroads into specific cultural settings and life worlds. I sense in these essays a similar concern about becoming the handmaidens of trialists/clinical epidemiologists, in effect helping keep the locals happy and participating in, but not interrogating, the underlying dynamics of power and privilege that characterize the HIV industry.

When we were working on Anthropology and Epidemiology we had little inkling of this looming reality. We imagined that partnerships with epidemiologists would revolve more around illuminating causal assemblages, experimenting with ways to resolve epistemological and methodological conflicts, and using the resulting insights to prevent sickness and suffering. Ours was an intellectual, scholarly vision that in retrospect was naive with regard to the social relations of science within the larger apparatus of what would become global public health. Dunn and I imagined two broad areas of research collaboration between anthropology and epidemiology. The first involved 'direct' collaboration between the disciplines through 'developing research designs, defining variables, testing specific hypotheses that have a social or cultural basis, and facilitating case-finding and casedefinition issues' (Dunn and Janes 1986, 27). We termed this 'anthropology in epidemiology', an enterprise that represented the 'actual association and active cooperation of epidemiologists and anthropologists' (ibid., 28). The second, contrasting area, involved indirect collaboration, meaning 'loose or tangential' cooperation: for example, in-depth investigation of causal factors identified in epidemiological research, using clues generated in epidemiological research for anthropological research and theory-building. This is what we termed 'epidemiology in anthropology': using anthropological tools to further preventionoriented research or programs. Direct collaboration, we saw, often involves anthropologists working both with, and as, epidemiologists. Indirect collaboration was more about using anthropological tools and expertise to extend the reach and applicability of epidemiology. While these roles still seem to accurately represent interdisciplinary possibilities, perhaps we need to extend this formulation to reconsider and critically evaluate the role of anthropologists within interventionist or implementation science (for example, Hardon and Pool 2016; Messac et al. 2013; Hopper 2013; Uretsky 2017). 
Scholarly partnerships depend on flexibility, tolerance of different perspectives, respect, and trust. While anthropologists often find occasion to criticize epidemiological approaches, and rightly so, I suspect that if the same critical eye were turned on anthropologists' own issues with interdisciplinary engagement the conclusions might lead to uncomfortable selfreflection. We are trained to be independent scholars, ruggedly so (this often surprises my colleagues in public health, where research initiatives are more collaborative). Our careers are based on our ability to engage critically as individuals with the subjects of our inquiry and to contribute to disciplinary knowledge and theory, and in the end depend on the creative logics with which we interpret and present social worlds to our fellow anthropologists. We are a profoundly self-referential bunch, a fact that gives us admirable strength of certainty about what we can and should contribute but that can get in the way of forming productive partnerships. Our traditional expectations for individual scholarship do not often prepare us well for interdisciplinary teamwork. Our strong allegiances interfere with our ability to see the value of other disciplines. Effective participation in the rough and tumble of interdisciplinary teamwork may require us to grudgingly accept that sometimes epidemiologists are capable of useful insights into the causes of and possible solutions to human suffering. There remains much to be gained in bridging the divide between these two critical disciplines.

\section{About the author}

Craig Janes is Professor and Director of the School of Public Health and Health Systems at the University of Waterloo, Ontario, Canada. His research has centered on the application of anthropology to public health and global health policy, with a specific focus on environmental change, social inequities and health, global health governance, the health impacts of global resource extraction, social factors associated with the emergence and outbreak of infectious diseases, and maternal and child health.

\section{References}

Adams, Vincanne, ed. 2016. Metrics: What Counts in Global Health. Durham, NC: Duke University Press.

Berkman, Lisa F., and S. Leonard Syme. 1979. 'Social Networks, Host Resistance and Mortality: A Nine-Year Follow-up of Alameda County Residents'. American Journal of Epidemiology 109: 186-204.

Dressler, William W. 2001. 'Medical Anthropology: Toward a Third Moment in Social Science?’ Medical Anthropology Quarterly 15, no. 4: 455-65. 
Dunn, Frederick L., and Craig R. Janes. 1986. 'Introduction: Medical Anthropology and Epidemiology'. In Anthropology and Epidemiology, edited by Craig R. Janes, Ron Stall, and Sandra M. Gifford, 3-34. Dordrecht, the Netherlands: D. Reidel Publishing.

Gorman, E. Michael. 1986. 'The AIDS Epidemic in San Francisco: Epidemiological and Anthropological Perspectives'. In Anthropology and Epidemiology: Interdisciplinary Approaches to the Study of Health and Disease, edited by Craig R. Janes, Ron Stall, and Sandra M. Gifford, 157-72. Dordrecht, the Netherlands: D. Reidel Publishing.

Gravlee, Clarence C. 2009. 'How Race Becomes Biology: Embodiment of Social Inequality'. American Journal of Physical Anthropology 139, no. 1: 47-57. https://doi.org/10.1002/ajpa.20983.

Hardon, Anita, and Robert Pool. 2016. 'Anthropologists in Global Health Experiments'. Medical Anthropology 35, no. 5: 447-51. https://doi.org/10.1080/01459740.2016.1177046.

Hopper, Kim. 2013. 'The Murky Middle Ground: When Ethnographers Engage Public Health'. Social Science \& Medicine 99: 201-204. https://doi.org/10.1016/i.socscimed.2013.10.025.

Inhorn, Marcia C., and Peter J. Brown. 1990. 'The Anthropology of Infectious Disease'. Annual Review of Anthropology 19: 89-117.

Inhorn, Marcia C., and Craig R. Janes. 2007. 'The Behavioural Research Agenda in Global Health: An Advocate's Legacy'. Global Public Health 2, no. 3: 294-312. https://doi.org/10.1080/17441690601010217.

Inhorn, Marcia C., and Emily A. Wentzell. 2012. 'Introduction: Medical Anthropology at the Intersections'. In Medical Anthropology at the Intersections: Histories, Activisms, and Futures, edited by Marcia C. Inhorn and Emily A. Wentzell, 1-20. Durham, NC: Duke University Press.

Janes, Craig R. 1990. Migration, Social Change and Health: A Samoan Community in Urban California. Palo Alto, CA: Stanford University Press.

Janes, Craig R., Kitty K. Corbett, James H. Jones, and James Trostle. 2012. 'Emerging Infectious Diseases: The Role of Social Sciences'. Lancet 380, no. 9857: 1884-86. https://doi.org.10.1016/S0140-6736(12)61725-5.

Janes, Craig R., Ron Stall, and Sandra M. Gifford, eds. 1986. Anthropology and Epidemiology: an Interdisciplinary Approach to the Study of Health and Disease. Dordrecht, the Netherlands: D. Reidel Publishing.

Kark, J. D., and J. H. Abramson. 2003. 'Sidney Kark's Contributions to Epidemiology and Community Medicine’. International Journal of Epidemiology 32, no. 5: 882-84. https://doi.org/10.1093/ije/dyg291.

Krieger, Nancy. 2001. 'Theories for Social Epidemiology in the 21 st Century: An Ecosocial Perspective'. International Journal of Epidemiology 30, no. 4: 668-77. 
Krieger, Nancy. 2005. 'Embodiment: A Conceptual Glossary for Epidemiology'. Journal of Epidemiology and Community Health 59, no. 5: 350-55. https://doi.org/10.1136\%2Fjech.2004.024562.

Krieger, Nancy. 2011. Epidemiology and the People's Health: Theory and Context. New York: Oxford.

Leighton, Alexander. 1959. My Name Is Legion: Foundations for a Theory of Man in Relation to Culture. New York: Basic Books.

Leighton, Alexander, A. T. Lambo, and Charles C. Hughes. 1963. Psychiatric Disorder among the Yoruba. Ithaca, NY: Cornell University Press.

Leighton, Dorothea, John S. Harding, David H. Macklin, Allister M. Macmillan, and Alexander H. Leighton. 1963. The Character of Danger: Psychiatric Symptoms in Selected Communities. New York: Basic Books.

Marmot, Michael G., and S. Leonard Syme. 1976. 'Acculturation and Coronary Heart Disease in Japanese Americans’. American Journal of Epidemiology 104: 225-47.

Messac, Luke, Dan Ciccarone, Jeffrey Draine, and Philippe Bourgois. 2013. 'The GoodEnough Science-and-Politics of Anthropological Collaboration with Evidence-based Clinical Research: Four Ethnographic Case Studies'. Social Science \& Medicine 99: 176-86. https://doi.org/10.1016/j.socscimed.2013.04.009.

NSF (National Science Foundation). 2017. 'Ecology and Evolution of Infectious Diseases'. https://www.nsf.gov/funding/pgm summ.jsp?pims id=5269.

Paul, Benjamin D., ed. 1955. Health, Culture, and Community: Case Studies of Public Reactions to Health Programs. New York: Russell Sage Foundation.

Singer, Merrill. 2014. Anthropology of Infectious Disease. Walnut Creek, CA: Left Coast Press.

Singer, Merrill, Nicola Bulled, Bayla Ostrach, and Emily Mendenhall. 2017. 'Syndemics and the Biosocial Conception of Health'. Lancet 389, no. 10072: 941-50. https://doi.org.10.1016/S0140-6736(17)30003-X.

Syme, S. Leonard. 2005. 'Historical Perspective: The Social Determinants of Disease - Some Roots of the Movement'. Epidemiologic Perspectives and Innovations 2, no. 2: 1-7.

Trostle, James. 1986a. 'Anthropology and Epidemiology in the Twentieth Century: A Selective History of Collaborative Projects and Theoretical Affinities, 1920 to 1970'. In Anthropology and Epidemiology: Interdisciplinary Approaches to the Study of Health and Disease, edited by Craig R. Janes, Ron Stall, and Sandra M. Gifford, 59-94. Dordrecht, the Netherlands: D. Reidel Publishing.

Trostle, James. 1986b. 'Early Work in Anthropology and Epidemiology: From Social Medicine to the Germ Theory, 1840 to 1920'. In Anthropology and Epidemiology: Interdisciplinary Approaches to the Study of Health and Disease, edited by Craig R. Janes, Ron Stall, and Sandra M. Gifford, 35-58. Dordrecht, the Netherlands: D. Reidel Publishing. 
Trostle, James. 2005. Epidemiology and Culture. New York: Cambridge University Press.

Trostle, James A., Alan Hubbard, James Scott, William Cevallos, Sarah Bates, and Joseph N. S. Eisenberg. 2008. 'Raising the Level of Analysis of Food-Borne Outbreaks: FoodSharing Networks in Rural Coastal Ecuador'. Epidemiology 19, no. 3: 384-90.

Tsai, Alexander C., Emily Mendenhall, James A. Trostle, and Ichiro Kawachi. 2017. 'Cooccurring Epidemics, Syndemics, and Population Health'. Lancet 389, no. 10072: 978-82. https://doi.org.10.1016/S0140-6736(17)30403-8.

Uretsky, Elanah. 2017. “We Can't Do That Here”: Negotiating Evidence in HIV Prevention Campaigns in Southwest China'. Critical Public Health 27, no. 2: 205-216. https://doi.org/10.1080/09581596.2016.1264571.

Wilson, David. 2017. 'The World Bank and Health in a Changing World'. Paper presented at the Balsillie School for International Affairs, Waterloo, Ontario, Canada, 16 January. 